\title{
Criminosos, Fugitivos e Litigantes pela Liberdade: os Escravos Traficados para Campinas, 1860-1888
}

\author{
Criminal, Fugitives and Litigants for Freedom: \\ the Slaves Traded to Campinas, 1860-1888
}

\author{
Leticia Graziele de Freitas Lemes ${ }^{1}$ \\ legrafreitas@gmail.com
}

Resumo

Este texto traz algumas considerações iniciais, que são parte integrante de um projeto de mestrado que vimos desenvolvendo na Universidade Estadual de Campinas, cuja proposta é analisar o impacto do tráfico interno na vida dos indivíduos comercializados na segunda metade do século XIX e a sua importância para a resistência e as mobilizações cativas contra a escravidão no Sudeste. Assim, apresentamos alguns dados obtidos através do cruzamento de processos criminais envolvendo escravos, ações de liberdade e anúncios de fugas de cativos no jornal Gazeta de Campinas, com os registros do pagamento do imposto da Meia Sisa na Coletoria e Recebedoria de Rendas de Campinas, que indica as transações de compra e venda de cativos no período de 1860 a 1884. O objetivo deste artigo é trazer alguns elementos para a discussão sobre a relação entre os eventos retratados pelas fontes privilegiadas e a experiência do tráfico na vida desses cativos.

Palavras-chave: Tráfico interno de escravos; Experiência escrava; Resistência escrava.

\section{Abstract}

This text brings some still preliminary considerations, which are part of a master's project that we have developed at the Universidade Estadual de Campinas (UNICAMP), whose goal is to analyze the impact of internal slave trade in the lives of individuals sold in the second half of the nineteenth century and its importance for strength and captive mobilizations against slavery in the Southeast. Thus, we present some data obtained through the intersection of criminal cases involving slaves, disputes for freedom in court and captive escapes announced in the newspaper Gazeta de Campinas, with the records of the payment of the Meia Sisa tax at the Coletoria e Recebedoria de Rendas de Campinas, which indicates the transactions of captives in the period from 1860 to 1884 . The objective of this paper is to provide some elements for discussion on the pertinence of the experience of the trade in the lives of captives for the events delineated by the privileged sources.

Keywords: Internal Slave Trade; Slave Experience; Slave Resistance.

1 Mestranda em História Social na Universidade Estadual de Campinas (Unicamp), desde 2013. Bolsista da Fundação de Amparo à Pesquisa do Estado de São Paulo (FAPESP). 
Notas de Pesquisa

\section{Introdução}

Eram os idos de 1875 quando o agente comercial Antônio Teixeira Marinho trouxe do Rio de Janeiro um comboio de escravos para ser vendido no município paulista de Campinas. Chegaram à cidade no fim do dia e passaram a noite em uma casa "destinada para isso". Na casa, um grande número de escravos dormia em comum na sala, enquanto Marinho e duas raparigas dormiam em um quarto a parte. Ao amanhecer, o agente comercial foi chamado pelos cativos Antônio Baiano e Francisco mulato para verificar um escravo que estaria enfermo a um canto do dormitório.

Apenas Marinho chegou-se ao enfermo, saltou, de improviso, o referido Francisco, de machado alçado, e deu-lhe alguns golpes que o lançara por terra com o crânio fraturado (...). Feito isso, correu Antônio Baiano a fechar a porta, Francisco foi também a outra porta, e ambos intimaram a todos - que dali não saíssem (...). Então Antônio deu mais uma pancada de machado em Marinho, certamente com esse mesmo machado com que Francisco o ferira e deixara no lugar. ${ }^{2}$

Após realizarem o ato criminoso, os dois escravos foram ao aposento de Marinho em busca do que lá pudessem encontrar, e convidaram as duas raparigas que ali estavam para fugirem com eles, o que não teriam aceitado. Depois, enquanto Francisco e Antônio guardavam as saídas para que os demais escravos não fossem avisar a ninguém, um terceiro cativo, chamado Guilherme, pegou os papéis que o agente comercial guardava em canastras no aposento e levou para fora para que pudesse inutiliza-los, destruindo desse modo as provas da propriedade dos cativos adquiridos por Marinho para a venda.

Enquanto avaliava os papéis encontrados nas canastras, Guilherme não se deu conta da fuga do cativo Luís, que conseguiu sair da casa e avisar a autoridade. Os cativos foram todos levados à delegacia, onde os depoimentos foram tomados e um processo criminal teve início com o indiciamento dos escravos Francisco, Antônio e Guilherme.

Narrativa semelhante a esta foi contada pelo historiador Sidney Chalhoub na obra Visões da liberdade (1990), onde o comerciante José Moreira Veludo foi atacado pelos escravos que ele dispunha para vender em sua loja na Corte do Rio de Janeiro. Diferente de Veludo, no entanto, o agente comercial Marinho não sobreviveu ao ataque.

Outros aspectos, todavia, são semelhantes nas duas histórias e ajudam a levantar alguns questionamentos sobre a escravidão no Sudeste na segunda metade do século XIX.

Assim como os escravos da loja de Veludo, o grupo de cativos que pernoitaram com Marinho em Campinas estava destinado à venda e era nascido em diferentes províncias do Império. A maioria deles, nos dois casos, era formada por cativos oriundos das províncias do Norte.

Chalhoub (1990, p. 43-53) aponta em sua análise para a importância que o contexto de intensificação do tráfico interno de cativos no período teve para a história do levante na loja de Veludo. Os escravos que participaram desse ato criminoso na Corte, assim como os que assassinaram Marinho em Campinas, haviam sido trazidos ao "local do crime" através do tráfico interprovincial e buscavam interferir em seus destinos para além do arbítrio dos negociantes.

Junto com eles, muitos cativos foram trazidos das províncias do Norte, Centro ou Sul do Império para o Sudeste na segunda metade do século XIX, quando o fechamento do tráfico transatlântico de escravos, pela lei Eusébio de Queirós, de 1850, causou o reajuste dos negócios da escravidão. Para suprir a necessidade de mão-de-obra nas crescentes regiões cafeeiras do Sudeste, os negociantes de escravos investiram fortemente no tráfico interno, resultando em um volume de pelo menos 200 mil cativos transacionados dentro do Império no período (SLENES, 1976, p. 138). Além disso, se contabilizarmos o comércio intrarregional de escravos, isto é, entre as províncias e municípios da própria região Sudeste, é provável que os números do tráfico interno sejam o dobro (GRAHAM, 2002, p. 129; SLENES, 1976, p. 135).

No processo criminal ocorrido em Campinas, parece evidente que os escravos indiciados pelo

2 Campinas. Arquivo Edgard Leuenroth (AEL), Fundo Autos Crimes em São Paulo (CSP), Seção Processos Crimes do Interior - Campinas (ACI), Microfilme CSP 231, Documento 004. Processo Crime. Réus: Antônio, Francisco, e Guilherme, escravos de José Júlio de Barros, Campinas, 1874. 
assassinato do agente comercial Marinho estavam tentando evitar sua venda no município. Pelo depoimento dos outros escravos que estavam em poder do comerciante, soubemos que pelo menos um dos indiciados teria lutado para não ser embarcado no Rio de Janeiro e outro teria dito "que aqui não seria vendido, por que ao sair a [sic] rua havia de fazer um espalhafato tal que o tornasse invendável" 3 .

Como a possibilidade de ser vendido para a região do café era cada vez maior ao longo da segunda metade do século (GRAHAM, 2002, p. 122), é pertinente que se compreenda melhor o impacto do tráfico interno na vida desses homens e mulheres escravizados. As vendas representavam a desestabilização das condições de cativeiro nas quais os escravos estavam inseridos há certo tempo, com alterações nas políticas de domínio e na relação com o senhor a que estavam sujeitos. Além disso, esses indivíduos tiveram que lidar com a separação de familiares e a desestruturação de redes de solidariedade consolidadas nos locais em que residiam (CHALHOUB, 2009, p. 55).

Além do caso do assassinato do comerciante Marinho, a documentação criminal de Campinas está recheada de assassinatos e ofensas físicas graves praticadas por cativos aos seus senhores ou feitores, especialmente no ambiente das fazendas de café. A bibliografia sobre a escravidão tem concordado que houve um acirramento das tensões em torno da questão escravista na segunda metade do século XIX, em especial nas áreas cafeeiras do Sudeste (AZEVEDO, 1987; SLENES, 1986). Historiadores como Hebe Maria Mattos de Castro (1997), Eduardo Pena (2006), José Hilário Ferreira Sobrinho (2011), e Richard Graham (2002), por exemplo, ressaltam a relevância da intensificação do tráfico interprovincial de cativos como um dos principais fatores a moldar esse processo.

Richard Graham (GRAHAM, p. 122) defende que a dolorosa experiência do tráfico interno contribuiu sobremaneira para o aumento da resistência escrava e a progressiva perda da autoridade senhorial sobre esses mesmos cativos. Eduardo Spiller Pena (PENA, p. 190) analisou de modo semelhante o crescimento das revoltas escravas no período, concluindo que esses indivíduos "tenderam a resistir ao comércio interno sobre sua vida e seu corpo".

Hebe Castro, por sua vez, chama a atenção para a troca de experiências e valores entre os escravos estabelecidos nas fazendas de café e os "escravos novos", oriundos do tráfico interprovincial, que traziam consigo uma "bagagem de práticas costumeiras":

Antes da extinção do tráfico [transatlântico], os cativos de maiores recursos comunitários pressionaram mais por privilégios do que por direitos. [...] A originalidade da argumentação dos cativos negociados no trafico interno, nas últimas décadas da escravidão, está no sentido genérico que atribuíam ao 'mau cativeiro' e na positividade que emprestavam ao 'bom cativeiro', sem o qual o senhor não merecia obediência (CASTRO, 1997, p. 359).

Maria Helena Machado (1994), por outro lado, não concorda que tenha sido o tráfico interno o responsável pelo aumento das reações violentas dos escravos nas últimas décadas da escravidão, mas sim a rigidez cada vez maior do sistema disciplinar das fazendas, que solapava as margens de autonomia escrava, gerando tensões em torno daquilo que os cativos entendiam como direitos.

Este artigo é parte de um estudo que visa avaliar se o incremento do tráfico interno contribuiu de modo relevante para o aumento dessas mobilizações escravas em áreas de grande lavoura em expansão. Para isso, realizamos o cruzamento dos dados encontrados em processos criminais envolvendo escravos ${ }^{4}$, ações de liberdade ${ }^{5}$ e anúncios de fugas de cativos no jornal Gazeta de Campinas ${ }^{6}$, com os registros do pagamento do imposto da Meia Sisa na Coletoria e Recebedoria de Rendas de Campinas ${ }^{7}$, que indica as transações de compra e venda de cativos no município no período de 1860 a 1884. Essas fontes nos permitem encontrar os

3 AEL, CSP, ACI, Microfilme CSP 231, Documento 004. Processo Crime. Réus: Antônio, Francisco, e Guilherme, escravos de José Júlio de Barros, Campinas, 1874.

4 Arquivo Edgard Leuenroth (AEL), Fundo Autos Crimes em São Paulo (CSP), Seção Processos Crimes do Interior - Campinas (ACI), Campinas, 1860-1886.

5 Campinas. Centro de Memória - Unicamp (CMU), Tribunal de Justiça de Campinas (TJC), Ações de Liberdade, Campinas, $1860-1888$.

6 Gazeta de Campinas, 1859-1878.

7 Centro de Memória - Unicamp (CMU), Coletoria e Recebedoria de Rendas de Campinas (CRC), Registros da Meia Sisa de escravos da cidade de Campinas, 1860-1884. 
Notas de Pesquisa

escravos comercializados em Campinas já inseridos nas escravarias de destino, ou seja, possibilitam a apreensão de suas vidas após a experiência da venda. Desta feita, é possível investigarmos aspectos da experiência vivida pelos indivíduos que foram conduzidos pelo tráfico interno para uma região de cafeicultura que se configurou como importante local de destino dos homens e mulheres transacionados na segunda metade do século XIX - o município de Campinas.

Tendo em vista os estudos historiográficos que privilegiaram, em grande medida, os aspectos econômicos e demográficos ou as experiências cativas do tráfico interno nas áreas exportadoras de escravos (FERREIRA SOBRINHO, 2011; SCHEFFER, 2012; MOTTA, 2012; CHALHOUB, 1990; ROCHA, 2004), pretendemos aprofundar uma análise da experiência da reconstrução de suas vidas nos locais de destino $^{8}$.

Os historiadores já observaram que existe uma presença massiva de escravos nascidos em outras províncias entre aqueles que figuraram nos processos criminais do Sudeste. Todavia, como argumenta Maria Helena Machado (1987, p. 51), isso poderia simplesmente refletir a realidade demográfica de Campinas, cuja população escrava de 1 a 39 anos registrada na matrícula de 1873 apresenta uma proporção de 81\% de cativos oriundos das províncias do Norte e Nordeste do Império (SLENES, 1976, p. 192).

Portanto, discutir a relevância do tráfico interno para as mobilizações escravas nas décadas finais da escravidão exige que se vá além da observação das origens dos cativos criminosos. A análise conjunta de outras fontes que trazem esses indivíduos forasteiros, para observá-los além do crime, isto é, em litígios pela liberdade e em fugas, possibilita apreender outros elementos da vida do cativo trazido à Campinas, como, por exemplo, as novas alianças que foram constituídas - ou não - nas escravarias de destino.

Neste texto, por sua vez, apresentamos dados colhidos na documentação que permitem discutir alguns pontos a respeito da relação entre os eventos retratados pelas fontes privilegiadas (crimes, fugas e litígios pela liberdade) e a experiência do tráfico na vida desses cativos.

\section{Forasteiros ${ }^{9}:$ os escravos traficados para Campinas}

Assim como já observado a respeito da predominância de cativos do Norte e Sul do Império nos atos criminosos no Sudeste, as fontes por nós inquiridas mostram que, de fato, há uma enorme proporção dos escravos nascidos em outros municípios entre os envolvidos em processos criminais ou de liberdade, ou que fugiram de seus senhores na segunda metade do século XIX em Campinas ${ }^{10}$ (ver Tabela 1). Apenas 11\% dos cativos crioulos presentes nessas fontes nasceram no município de Campinas. Assim, podemos considerar que pelo menos $71,6 \%$ dos cativos crioulos presentes nessas fontes eram forasteiros que chegaram ao município paulista através do tráfico interno ${ }^{11}$. Essa proporção aumenta para $91,3 \%$ se contabilizarmos os cativos africanos e os crioulos sem especificação de localidade de origem que estão presentes na documentação. $\mathrm{O}$ percentual de cativos nascidos no Norte, Sul ou Centro do Império chega a 47,3\% de todos os nascidos no Brasil.

A busca nominal dos cativos réus, vítimas, litigantes e fugitivos nos registros de meia sisa mostra ainda que o tráfico interno, ou comércio local, foi importante também para a experiência dos escravos nascidos em Campinas, uma vez que 48,7\% dos que aparecem nessas fontes também haviam passado por transações de compra e venda na segunda metade do século XIX.

Isto posto, considerando tanto os escravos nascidos em Campinas como os oriundos de outras localidades, observamos que pelo menos $35,6 \%$ dos cativos envolvidos em crimes, fugas e ações de liberdade na segunda metade do século XIX já haviam passado pela experiência de compra e venda pelo menos uma vez em sua vida.

8 Destaca-se, nessa linha de análise, o trabalho de Hebe Castro (1997), em que a autora observa a importância dos laços familiares dos escravos e a troca de experiências entre os cativos das fazendas e os oriundos do tráfico para mudanças nas ações de liberdade e crimes dos escravizados após 1850.

9 Expressão emprestada de Oliveira (2012).

10 Temos informação de origem para 41,7\% dos cativos encontrados nessa documentação. Os percentuais mostrados a seguir foram calculados com base no total de cativos com informação de origem.

11 Vale ressalvar que alguns desses cativos podem ter chegado à Campinas em companhia de seus senhores, em processos de migração interna. 
Logo, o exame dos três fundos documentais permite perceber o protagonismo dos escravos oriundos do tráfico interno também em litígios pela liberdade e fugas, e não apenas nos registros da criminalidade escrava. Ao invés de desprezar esses dados por refletirem a realidade demográfica do município, vale considerar que a experiência do tráfico foi um elemento compartilhado por quase metade dos indivíduos escravizados que, de algum modo, perturbaram o domínio senhorial em Campinas após 1860, o que pode ter sido determinante para as ações escravas que podemos vislumbrar na documentação.

\section{Tabela 1: Origem dos escravos em Processos Criminais, Ações de Liberdade e anúncios de fuga (CAMPINAS, 1860-1888)}

\begin{tabular}{|c|c|c|c|c|}
\hline Local de origem & $\begin{array}{c}\text { Número de } \\
\text { escravos }\end{array}$ & $\begin{array}{c}\text { \% sobre o total com } \\
\text { origem informada }\end{array}$ & $\begin{array}{c}\text { \% sobre o total de } \\
\text { nascidos no Brasil }\end{array}$ & \% sobre o total de escravos \\
\hline Campinas & 39 & 8,7 & 9,8 & 4,6 \\
\hline Província de São Paulo* $^{*}$ & 56 & 12,4 & 14 & 6,6 \\
\hline Região Sudeste** $^{*}$ & 53 & 11,8 & 53,3 & 25 \\
\hline Outras regiões & 213 & 47,3 & 9,5 & 4,4 \\
\hline Crioulos*** & 38 & 8,4 & - & 6 \\
\hline Africanos & 51 & 11,3 & - & 52,7 \\
\hline Total de informações de origem & 450 & 100 & - & 47,2 \\
\hline Origem não informada & 403 & - & 100 & 46,8 \\
\hline Total nascidos no Brasil & 399 & 85,7 & - & 100 \\
\hline Total de escravos & $\mathbf{8 5 3}$ & - & & \\
\hline
\end{tabular}

Fontes: Centro de Memória - Unicamp (CMU), Tribunal de Justiça de Campinas (TJC), Ações de Liberdade, Campinas, 1860-1888; Arquivo Edgard Leuenroth (AEL), Fundo Autos Crimes em São Paulo (CSP), Seção Processos Crimes do Interior - Campinas (ACl), Campinas, 1860-1886; Gazeta de Campinas, 1859-1878. *Não inclui os nascidos em Campinas. **Não inclui os nascidos na Província de São Paulo. *** Localidade de origem dentro do Império não foi especificada, por isso, não contabilizamos esses $9,5 \%$ no total de escravos crioulos forasteiros.

\section{IMAGEM 1 - ANÚNCIO DE FUGA DOS ESCRAVOS} JosÉ E Vitoriano.

\section{Rs. $100 \not 000$}

0 abaixo assignado gratifica com a quantia acima a quem prender e entregar-lhe qualquer dos seus escravos fugidos de nomes José e Victoriano, com as seguintes signaes :

José, alto, espigado, mulato escuro, boa dentadnra, pés grandes, sem barba, fllho do Bethlém de Jundialyy, onde tem a mae. Tem um dedo d'uma das mañ mais encolhido que os outros. For comprado no Amparo ao sr. Antonio Joaquim de Souza Braga em 6 de Dezembro do anno passado. Trabalha em olaria e é tambem carroceiro.

Victoriano, pedreiro, cồ fula, com 50 annos de idade mais ou menos, altura regular, pouca barba, com falta de alguns dentes na frente, falta-lhe bastante cabello, tem signaes de ventosas no peito $\mathrm{e}$ nunca deixa de andar de carapuça. Levou japona preta, calça de casimira azul e alguma roupa de algoda. Foi escravo do fallecido Manoel Rodrigues do Prado, crioulo de Cuyabá, d'onde veiu pequeno. Foi criado em Jundiahy onde tem parentes e em Bragança. Tem uma rendidura sobre a barriga.

Protesta-se com todo o rigor da lei contra quem os acoutar.

Campinas, 2 de Outubro de 1874.

Raphael Luiz Pereira da Silva.

Fonte: Gazeta de Campinas, 08/10/1874, edição nº 498.
A Tabela 1 permite observar que a proporção de cativos trazidos à Campinas pelo tráfico entre as regiões do Império foi muito grande, sinalizando experiências de grande afastamento de familiares e outras redes de solidariedade da terra natal.

Por outro lado, algumas das fontes permitiram saber que a venda para Campinas não havia sido a primeira a acontecer na vida do cativo, tendo ele sido traficado de outro local que não o do seu nascimento.

Nos anúncios de fuga na Gazeta de Campinas, há nas falas dos senhores a constante suspeita de que tais fugitivos teriam se dirigido aos lugares onde nasceram ou tinham algum parente, o que denota a percepção de que as fugas estavam ligadas ao comércio interno de almas. O caso de Vitoriano, que fugiu em outubro de 1874, é um exemplo interessante dessa possibilidade de análise. $\mathrm{O}$ anúncio de fuga (imagem 1) informa que Vitoriano nasceu em Cuiabá, Mato Grosso, mas foi criado em Jundiaí. Além disso, o anunciante observa que o cativo tem familiares em Bragança Paulista. Não encontramos seu registro de meia sisa, então não sabemos quando ele chegou a Campinas, mas o número de interferências que o tráfico causou em sua vida é bastante perceptível pela fonte. O senhor Antônio Rodrigues de Almeida também anunciou a fuga do seu escravo, de nome Tomé, em 1871, ressaltando que ele havia sido 
Notas de Pesquisa

trazido do Rio de Janeiro no ano anterior, mas teria sido levado para lá vários anos antes, tendo nascido na província de Minas Gerais. ${ }^{12}$

Essas falas, assim como a menção nos processos de liberdade sobre o local onde os cativos foram matriculados, permitem apreender lugares onde o escravo esteve antes de chegar a Campinas. A quantidade de informações é pequena, mas permite saber que pelo menos 12 escravos passaram pelo Rio de Janeiro antes de serem vendidos para Campinas, assim como 4 passaram por Minas Gerais, 3 estiveram na capital de São Paulo e 1 chegou a residir em Santos. A maior parte dos cativos com informação disponível, isto é, 21 deles, residiram em cidades vizinhas a Campinas antes de vir parar nas fontes que temos em mãos.

Para além do conhecimento dos locais onde os escravos estiveram, essas informações possibilitam saber que a experiência de compra e venda foi vivida mais de uma vez por esses sujeitos. Assim também, vivenciaram mais de uma vez as situações de rompimento de laços familiares e de solidariedade, bem como de práticas costumeiras na relação com os senhores, constituídos em diferentes lugares.

A dimensão do desenraizamento sofrido por esses indivíduos é um importante aspecto a ser considerado, isto é, devem-se levar em conta os diferentes tipos de experiência vividos por cativos vindos de localidades diversas e em momentos distintos. Afinal, é bastante improvável que ser um escravo recém-chegado em Campinas no começo da década de 1860 tenha sido a mesma coisa que em fins da década de 1870, por exemplo.

$\mathrm{Na}$ documentação judicial e anúncios de fuga analisados, verifica-se que a maioria dos escravos que figuraram como réus, vítimas, litigantes e fugitivos no período analisado, haviam sido adquiridos por seus atuais senhores entre 1870 e 1879. De modo análogo, os números do tráfico em geral, vislumbrados através dos registros do pagamento da meia-sisa, mostram que a maior parte das transações de compra e venda de cativos em Campinas ocorreram na década de 1870, totalizando 49,7\%, contra um percentual de $46,5 \%$ transacionado na década de 1860 , e apenas $3,7 \%$ na década final da escravidão.

Uma observação mais detalhada das datas de compra dos escravos em relação com as datas das ações de liberdade, crimes e anúncios de fugas em que os mesmos aparecem, mostra que 51,3\% dos cativos que se envolveram nesses eventos na década de 1870 tinham sido adquiridos pelos atuais senhores na mesma década, enquanto 47,8\% foram comprados no decênio anterior. Os eventos ocorridos na década de 1880 tiveram também a maioria dos cativos envolvidos comprados por seus senhores na década de 1870, com um percentual de 41,1\%, seguido pelos comprados nos anos 1860, com 37,5 pontos percentuais, e apenas 19,6\% comprados na própria década de 1880.

A maior frequência desses eventos nos anos 1870 pode estar relacionada ao fato de ter sido nessa década o aumento do tráfico entre as regiões do Império ${ }^{13}$, trazendo para o Sudeste indivíduos nascidos em locais mais distantes e que, por isso, experimentavam uma dimensão de desenraizamento mais profunda do que os cativos comercializados entre os municípios da própria província de São Paulo. É também razoável pensar que a grande proporção de cativos forasteiros dividindo o mesmo espaço em Campinas nesse momento tenha intensificado as tensões e possibilidades para a ação desses sujeitos, afinal, pelo menos a partir de meados dos anos 1870, a maioria da população escrava do município era formada por escravos nascidos no Norte do Império.

Além disso, algumas disposições legais a respeito do elemento servil no Império contribuem para explicar a frequência desses acontecimentos na década de 1870. A partir da lei 2.040, promulgada em 28 de setembro de 1871, o direito de o escravo formar seu pecúlio e comprar sua liberdade foi formalizado. Isso explica, ao menos em parte, o aumento das ações de liberdade impetradas por escravos nos tribunais do Império após 1871, respondendo por $97 \%$ das ações de liberdade do Tribunal de Justiça de Campinas (ABRAHÃO, 1992, p. 6). Quase metade delas, isto é, 47,8\%, foram iniciadas para compra da alforria. E outros 12,1\% das ações consistiam em uma ação para depósito do pecúlio (ABRAHÃO, 1992, p. 7).

Somado a isso, na década de 1870 estavam vigentes duas determinações legais que diziam respeito à separação das famílias escravas em transações de venda e partilha. A primeira delas foi o decreto 1.695, promulgado em 15 de setembro de 1869, cujo artigo $2^{\circ}$ proibia, "sob pena de nulidade, separar o marido da mulher, o filho do

12 Gaz̧eta de Campinas, 10/03/1871, edição 138.

13 Slenes (1976, P. 126-132) observou que o comércio de escravos dentro da própria província de São Paulo era consideravelmente mais importante que o tráfico inter-regional no período de 1850 a 1870, respondendo pela demanda das regiões cafeeiras da província em um primeiro momento. 
pai ou mãe, salvo sendo os filhos maiores de 15 anos", nas vendas de escravos ${ }^{14}$. A lei 2.040, de 1871, por sua vez, estendeu essa proibição a todas as formas de alienação ou transmissão de escravos, mas diminuiu a idade dos filhos que não poderiam ser separados do pai ou mãe para 12 anos. ${ }^{15}$

Os registros do pagamento do imposto da meia sisa sobre as transações envolvendo escravos mostram, no entanto, que pelo menos 553 crianças escravas de até 12 anos foram vendidas em Campinas após 1871, e em apenas seis desses registros é mencionada a venda com um dos pais.

Desse modo, é importante olhar com atenção para a insegurança que as famílias escravas continuavam enfrentando mesmo após a promulgação dessas leis, o que pode ter sido um fator motivador para as ações que vemos nas fontes estudadas. Isto é, os indivíduos trazidos às lavouras cafeeiras com a experiência de tais rompimentos podem ter visto nesses regulamentos momentos propícios para lutar contra a separação de seus familiares.

Momentos propícios também devem ser investigados nas trajetórias de vida desses homens e mulheres escravizados. O início de um litígio pela liberdade, por exemplo, partia de uma análise do próprio cativo a respeito dos riscos advindos do enfrentamento judicial de seus senhores e as possibilidades de sucesso dentro de uma conjuntura que eles julgassem como favorável, ou como momentos limites, em que direitos estavam sendo ameaçados (FREITAS, 2012). Esses momentos limites também podem ter sido determinantes para os casos de escravos que fugiam do poder senhorial ou se envolviam em atos criminosos.

Um dos aspectos das trajetórias pessoais desses indivíduos que cabe ser inquirido é quanto tempo depois de vivenciar a experiência do tráfico, eles se envolveram nos eventos que aparecem nas fontes aqui analisadas, o que Maria Helena Machado chamou de "tempo de residência" ou "tempo de moradia" dos cativos nas fazendas ou com o atual senhor.

Na obra Crime e Escravidão, Maria Helena Machado (1987, p. 48-51) concluiu que a maioria dos réus escravos em Campinas não era formada por recém-chegados do "Norte", mas sim indivíduos residentes há certo tempo nas escravarias da qual faziam parte, podendo assim, ser considerados "enraizados", isto é, "escravos estáveis e conhecedores tanto da região em que habitavam, quanto das margens de acomodação do sistema ao qual estavam submetidos".

O tempo de moradia era informado pelos próprios cativos no interrogatório nos processos criminais e, com a busca nominal pelos registros do pagamento de meia sisa dos escravos mencionados nas fontes, pudemos encontrar tal informação para os documentos em que ela não constava. Com a observação do tempo de moradia dos escravos presentes nessas diversas fontes (Tabela 2) pudemos chegar a uma conclusão diferente da expressa por Machado. Averiguamos que o maior número de mobilizações escravas retratadas nessas fontes aconteceu nos primeiros cinco anos em poder do novo senhor, totalizando $60,8 \%$ dos eventos (somando-se a primeira e a segunda linha da Tabela 2). Isto pode indicar que a ação escrava tenha sido uma reação mais direta ao comércio sobre seus corpos.

Tabela 2: Tempo de moradia dos escravos em Processos Criminais, Ações de Liberdade e anúncios de fuga (CAMPINAS, 1860-1888)

\begin{tabular}{|c|c|c|c|}
\hline Tempo de moradia & Número de escravos & \% & \% acumulada \\
\hline Menos de um ano & 64 & 22,2 & 38,2 \\
\hline 1 a 5 anos & 111 & 19,4 & 60,8 \\
\hline 6 a 10 anos & 56 & 11,8 & 80,2 \\
\hline 11 a 15 anos & 34 & 6,6 & 92,0 \\
\hline 16 a 20 anos & 19 & 1,4 & 98,6 \\
\hline Mais de 20 anos & 4 & - & - \\
\hline Total de informações & $\mathbf{2 8 8}$ & & \\
\hline
\end{tabular}

Fontes: Centro de Memória - Unicamp (CMU), Fundo Tribunal de Justiça de Campinas (TJC), Ações de Liberdade, Campinas, 1860-1888; Fundo Coletoria e Recebedoria de Rendas de Campinas (CRC), Registros da Meia Sisa de escravos da cidade de Campinas, 1860-1884; Arquivo Edgard Leuenroth (AEL), Fundo Autos Crimes em São Paulo (CSP), Seção Processos Crimes do Interior - Campinas (ACl), Campinas, 1860-1886; Gazeta de Campinas, $1859-1878$.

Por outro lado, como observa Cristiany Rocha (2004, p. 248-51) a respeito das conclusões de Machado, o tempo de moradia não pode sozinho responder a questão sobre as relações entre o tráfico e as mobilizações escravas. Afinal, quanto tempo era necessário para que um cativo forasteiro deixasse de ser um "desenraizado"?

14 Decreto $^{\circ}$ 1.695, de 15 de setembro de 1869, artigo 2. Coleção das leis do Império do Brasil. Rio de Janeiro, Typ. Nacional, 1869 , p.129-30.

15 Lei 2.040, de 28 de setembro de 1871, artigo $7^{\circ}$. In: Lei 2.040, de 28 de setembro de 1871, sobre o estado servil, e decretos regulando a sua execução. São Paulo: Typ. Americana, 1872, p. 9. 
Notas de Pesquisa

Para aprofundar essa discussão, cruzamos os dados referentes ao tempo em que o escravo estava em poder do senhor com o seu local de origem (tabelas 3 a 6), de modo a indagar a dimensão do desenraizamento vivido nesses casos. O que verificamos então foi a aproximação dos momentos em que crimes, fugas e ações de liberdade se deram com as situações de compra dos escravos transacionados a partir do Norte ou Sul do Império, uma vez que $62,5 \%$ desses cativos vieram para Campinas pelo tráfico inter-regional há até cinco anos. Apenas entre os cativos nascidos em Campinas, essa proporção se inverte, sendo 43,8\% residentes com o atual senhor há até 5 anos, e 56,3\% os residentes de 6 a 20 anos. A localidade de origem que teve maior porcentagem de escravos envolvidos em crimes, fugas e ações de liberdade nos cinco primeiros anos de cativeiro com o atual senhor foi a Província de São Paulo, com um valor de 75\%, excluindo aí os nascidos no próprio município de Campinas.

\section{Tabela 3: Tempo de moradia dos escravos nascidos em Campinas quando se envolveram em CRimes, AÇõES DE LIBERDADE OU FUGAS}

\begin{tabular}{|c|c|c|c|}
\hline Tempo de moradia & Número de escravos & $\%$ & \% acumulada \\
\hline Menos de um ano & 1 & 6,3 & 6,3 \\
\hline 1 a 5 anos & 6 & 37,5 & 43,8 \\
\hline 6 a 10 anos & 5 & 31,3 & 75,0 \\
\hline 11 a 15 anos & 3 & 18,8 & 93,8 \\
\hline 16 a 20 anos & 1 & 0,0 & 100,0 \\
\hline Mais de 20 anos & 0 & - & - \\
\hline Total de informações & 16 & - \\
\hline
\end{tabular}

Fontes das tabelas 3 a 6: Centro de Memória da Unicamp (CMU), Fundo Tribunal de Justiça de Campinas (TJC), Ações de Liberdade, Campinas, 1860-1888; Fundo Coletoria e Recebedoria de Rendas de Campinas (CRC), Registros da Meia Sisa de escravos da cidade de Campinas, 1860-1884; Arquivo Edgard Leuenroth (AEL), Fundo Autos Crimes em São Paulo (CSP), Seção Processos Crimes do Interior - Campinas (ACI), Campinas, 1860-1886; Gazeta de Campinas, $1859-1878$.

Tabela 4: Tempo de moradia dos escravos nascidos na Província de São Paulo* quando se envolveram em CRIMES, Ações de Liberdade ou fugas

\begin{tabular}{|c|c|c|c|}
\hline Tempo de moradia & Número de escravos & $\%$ & \% acumulada \\
\hline Menos de um ano & 11 & 34,4 & 34,4 \\
\hline 1 a 5 anos & 13 & 40,6 & 75,0 \\
\hline 6 a 10 anos & 3 & 9,4 & 84,4 \\
\hline 11 a 15 anos & 3 & 6,3 & 93,8 \\
\hline 16 a 20 anos & 2 & 0,0 & 100,0 \\
\hline Mais de 20 anos & 0 & - & - \\
\hline Total de informações & 32 & - \\
\hline
\end{tabular}

* Não inclui os nascidos no município de Campinas.

Tabela 5: Tempo de moradia dos escravos nascidos nas províncias de Minas Gerais e Rio de Janeiro quando SE ENVOLVERAM EM CRIMES, Ações de Liberdade ou fugas

\begin{tabular}{|c|c|c|c|}
\hline Tempo de moradia & Número de escravos & $\%$ & \% acumulada \\
\hline Menos de um ano & 5 & 14,7 & 14,7 \\
\hline 1 a 5 anos & 18 & 52,9 & 67,6 \\
\hline 6 a 10 anos & 7 & 20,6 & 88,2 \\
\hline 11 a 15 anos & 3 & 8,8 & 97,1 \\
\hline 16 a 20 anos & 0 & 0,0 & 97,1 \\
\hline Mais de 20 anos & 1 & 2,9 & 100,0 \\
\hline Total de informações & $\mathbf{3 4}$ & & \\
\hline
\end{tabular}


Tabela 6: Tempo de moradia dos escravos nascidos fora da Região Sudeste quando se envolveram em CRimes, AÇÕES DE LIBERDADE OU FUGAS

\begin{tabular}{|c|c|c|c|}
\hline Tempo de moradia & Número de escravos & $\%$ & \% acumulada \\
\hline Menos de um ano (antes ou depois do evento) & 30 & 26,8 & 26,8 \\
\hline 1 a 5 anos & 40 & 35,7 & 62,5 \\
\hline 6 a 10 anos & 21 & 18,8 & 81,3 \\
\hline 11 a 15 anos & 15 & 13,4 & 94,6 \\
\hline 16 a 20 anos & 6 & 5,4 & 100,0 \\
\hline Mais de 20 anos & 0 & 0,0 & - \\
\hline Total de informações & $\mathbf{1 1 2}$ & - & - \\
\hline
\end{tabular}

Esses dados comprovam, ao menos em uma primeira análise quantitativa, que há uma importante relação entre as mobilizações escravas nos anos finais da escravidão e a experiência do tráfico interno nas vidas desses sujeitos. No entanto, consideramos que a questão ainda não está resolvida. Como dissemos a princípio, é necessário aprofundar o estudo dessa relação através de uma análise mais minuciosa dos crimes, ações de liberdade e episódios de fugas em que esses forasteiros se envolveram, de modo a compreender os significados que atribuíram a suas lutas e as alianças que formularam para tanto. ${ }^{16}$

Um exercício de cruzamento das fontes judiciais e cartoriais que se mostrou bastante instigante permite contar a historia da cativa Ursulina do Carmo, que iniciou ação cível em 1875 contra os herdeiros de seu falecido senhor para comprar a liberdade mediante a apresentação de seu pecúlio ${ }^{17}$. Durante o desenrolar do processo, os herdeiros tentaram por diversas formas impedir que a escrava se alforriasse. Em determinado momento, questionaram qual seria a origem do pecúlio possuído por Ursulina. A resposta a esse questionamento ocasionou uma singular revelação:

(...) respondeu ter o acumulado em virtude de seu trabalho e de doações pequenas que lhe fizeram algumas pessoas, tendo recebido algum dinheiro de sua mãe que lhe mandou da província do Paraná e também de sua irmã, forra existente nessa cidade, que se a quantia exibida for insuficiente para completar o preço da indenização do seu justo valor, tenciona obter o que faltar, pedindo ou por empréstimo a alegue que se queira confiar para depois de liberta pagar, ou empenhando-se com sua irmã Leocádia do Carmo que lhe forneça a quantia precisa (...). ${ }^{18}$

Procuramos pelo registro do pagamento da meia sisa da compra da escrava Ursulina, mas ele não foi encontrado. Todavia, ao investigar se o seu falecido senhor, o Comendador Francisco Teixeira Vilella, havia adquirido ou vendido algum escravo no período, obteve-se um resultado bastante interessante, que elucida as possibilidades dos cruzamentos entre essas fontes para o tipo de análise proposta na pesquisa.

Os registros de meia sisa revelaram que, entre os anos de 1864 e 1868, Vilella adquiriu 307 novos escravos. Entre eles encontra-se a referida irmã de Ursulina, que teria lhe emprestado dinheiro para compra de sua alforria. A irmã se chamava Leocádia e fora comprada em meio a um enorme grupo de cativos adquiridos de uma só vez pelo comendador e registrado nos livros da meia sisa em fevereiro de 1868. Esse grupo continha 186 cativos e compunha uma comunidade escrava que existia há muitos anos na fazenda de Capão Alto em Castro, no Paraná. Apesar de o registro do pagamento da meia sisa atinente à compra de Ursulina não ter sido encontrado, tudo leva a crer que ela fazia parte desse mesmo grupo.

Com os dados presentes na Ação de Manumissão e nos registros da meia sisa, e com consulta à bibliografia (OLIVEIRA, 2012; PENA, 2006), foi possível divisar vários elementos das trajetórias de vida dessas duas mulheres: elas nasceram em Curitiba - PR e viviam em meio a várias famílias escravas na fazenda Capão Alto. Quando Leocádia e Ursulina tinham por volta de 18 e 37 anos, respectivamente, uma transação entre o

16 Um interessante trabalho nesta linha foi feito por Oliveira (2013).

17 Campinas. Centro de Memória - Unicamp (CMU), Tribunal de Justiça de Campinas (TJC), 2º Ofício, Processo 1669, Caixa 95. Ação de Manumissão. Autor: Ursulina do Carmo, escrava de Francisco Teixeira Vilela, Campinas, 1875-1876.

18 CMU, TJC, $2^{\circ}$ Ofício, Processo 1669, Caixa 95. Ação de Manumissão. Autor: Ursulina do Carmo, escrava de Francisco Teixeira Vilella, Campinas, 1875-1876. 
Notas de Pesquisa

Comendador Vilella e a firma Gavião Ribeiro \& Gavião as trouxe para Campinas. A mãe das irmãs, todavia, permaneceu na localidade de origem. Aqui, conseguiram juntar certa quantia em dinheiro, que usaram para adquirir suas liberdades. Outro detalhe interessante sobre essas mulheres foi com relação ao sobrenome que Ursulina menciona no processo de liberdade: "do Carmo". A fazenda Capão Alto fora por muito tempo administrada pela ordem dos Carmelitas, o que justifica a adoção do sobrenome "do Carmo" pelas duas irmãs, e também por outros cativos adquiridos pelo comendador naquela transação, como é possível ver nos registros da meia sisa.

Buscando essas pessoas em outras fontes documentais, verificamos que Leocádia foi acusada de tentativa de homicídio, em setembro de $1867 .{ }^{19}$ Junto com ela, outros dois escravos foram citados como réus: Januário e Candido. Voltando aos registros de meia sisa, encontramos esses dois homens em outro grupo adquirido por Vilella em 1864. Januário era natural de Mogi das Cruzes - SP, e Candido, natural do Ceará. ${ }^{20}$

Os três cativos eram acusados pela tentativa de assassinato de dona Maria Leopoldina de Godoy, descrita no processo como amante de Francisco Teixeira Vilella. O processo também aponta que Leocádia fora destinada por Vilella a servir na casa de dona Leopoldina, sendo afastada de seus companheiros de Capão Alto, que permaneciam em uma fazenda do comendador.

Durante o processo, surgiu a acusação de que o senhor teria articulado o plano de matar a amante, com os serviços dos três escravos, e, em troca, teria lhes prometido a liberdade. No entanto, o plano se a suspeita fosse verdadeira - não saiu como esperado, nem para o comendador, nem para os cativos: a amante sobreviveu, o caso amoroso veio a público e as alforrias prometidas nunca foram concedidas. Leocádia adquiriu sua liberdade anos depois, em 1873, mediante a compra por seu pecúlio. ${ }^{21}$ Verificando outra fonte documental, qual seja o inventário post mortem de Francisco Teixeira Vilella, foram encontrados os outros dois réus, Januário e Candido, ainda escravos em 1873.22

No inventário, foi possível também observar que Leocádia e Ursulina, bem como outros cativos do comendador, estiveram doentes e foram tratados por um médico requerido pelo próprio senhor. ${ }^{23}$ De fato, no processo em que litigou por sua liberdade, Ursulina alegou ser "doentia", o que foi comprovado pelos peritos que a examinaram para arbitrar o preço de sua liberdade. ${ }^{24}$

Apesar de tantos detalhes sobre a trajetória das irmãs, ainda uma pergunta se impõe diante das palavras de Ursulina, reproduzidas algumas páginas atrás: como a mãe, residente na Província do Paraná, teria lhe enviado a quantia que a ajudou a comprar a liberdade em 1875? Como a família mantinha contato mesmo com tantos quilômetros de distância?

Em sua Dissertação de Mestrado, Joice Oliveira analisou de forma minuciosa a comunidade escrava pertencente ao Comendador Francisco Teixeira Vilella, e formulou uma hipótese muito interessante para responder essas perguntas sobre as famílias de Capão Alto:

Acreditamos que Ursulina contava com solidariedade de seu companheiro Virgilino (...) [. Ele] exercia o ofício de tropeiro na comunidade de Santa Maria [fazenda de Vilella], o que deve tê-lo permitido manter contato com seus companheiros, os quais ficaram no Paraná e assim levava notícias e encomendas de um canto a outro (OLIVEIRA, 2012, p. 187).

Histórias como a de Ursulina e Leocádia do Carmo elucidam alguns aspectos da experiência vi-

19 Apesar do registro da meia sisa sobre a compra dos escravos de Capão Alto constar em fevereiro de 1868, a presença de Leocádia neste processo no ano interior leva a crer que a transação ocorrera também em 1867. Campinas. Arquivo Edgard Leuenroth (AEL), Fundo Autos Crimes em São Paulo (CSP), Seção Processos Crimes do Interior - Campinas (ACI), Microfilme CSP 215, Documento 004. Processo Crime. Réus: Januário, Cândido e Leocádia, escravos de Francisco Teixeira Vilella, 1867.

20 AEL, CSP, ACI, Microfilme CSP 215, Documento 004. Processo Crime. Réus: Januário, Cândido e Leocádia, escravos de Francisco Teixeira Vilella, 1867, "Autos de qualificação dos réus".

21 AEL, Fundo Peter Eisenberg, Fichas de Peter Eisenberg, Alforrias de escravos, Pasta 2, ficha n544. Fonte citada por Oliveira (2012, p. 186).

22 CMU, TJC, $1^{\circ}$ Ofício, Processo 4359, Caixa 211. Inventário post mortem do Comendador Francisco Teixeira Vilella, 1873.

23 CMU, TJC, $1^{\circ}$ Of., P. 4359, Cx. 211. Inventário post mortem do Comendador Francisco Teixeira Vilella, 1873, "Recibo médico".

24 CMU, TJC, $2^{\circ}$ Ofício, Processo 1669, Caixa 95. Ação de Manumissão. Autor: Ursulina do Carmo, escrava de Francisco Teixeira Vilella, Campinas, 1875-1876. 
vida e das estratégias de escravos que foram comercializados em Campinas após o fechamento do tráfico atlântico. Ursulina chegou ao local de destino na companhia da irmã e contou com sua ajuda para conquistar sua liberdade algum tempo depois. De modo semelhante, outros cativos forasteiros buscaram adquirir sua liberdade no Tribunal de Justiça de Campinas, ou tentaram escapar das fazendas campineiras através de fugas ou crimes. Um exame detido das particularidades de suas histórias é um passo importante para avaliar se, de fato, o incremento do tráfico interno de escravos na segunda metade do século XIX contribuiu decisivamente para o aumento da resistência escrava nas regiões de grande lavoura em expansão.

\section{Fontes manuscritas}

\section{Centro de Memória - Unicamp (CMU):}

Fundo Tribunal de Justiça de Campinas (TJC), Ações de Liberdade, Campinas, 1860-1888. Inventários post mortem, Campinas, 1860-1888.

Fundo Coletoria e Recebedoria de Rendas de Campinas (CRC), Registros da Meia Sisa de escravos da cidade de Campinas, $1860-1884$.

\section{Arquivo Edgard LeUenRoth - Unicamp (AEL):}

Fundo Autos Crimes em São Paulo (CSP), Seção Processos Crimes do Interior - Campinas (ACI), Campinas, 1860-1886.

\section{Fontes impressas}

A Gazeta de Campinas, 1859-1878.

Coleção das leis do Império do Brasil, Rio de Janeiro, Typ. Nacional, 1869.

Lei 2.040, de 28 de setembro de 1871, sobre o estado servil, e decretos regulando a sua execução. São Paulo: Typ. Americana, 1872.

\section{Referências}

ABRAHÃO, Fernando Antônio. As ações de liberdade de escravos do Tribunal de Campinas. Campinas: UNICAMP/CMU, 1992.

AZEVEDO, Célia M. M. de. Onda negra, medo branco: O negro no imaginário das elites século XIX. Rio de Janeiro: Paz e Terra, 1987.

CASTRO, Hebe M. M. de. Laços de família e direitos no final da escravidão. In: NOVAIS, Fernando (Coord.). História da vida privada no Brasil: Império. São Paulo: Companhia das Letras, 1997. p. 337-383.

CHALHOUB, Sidney. Costumes senhoriais: escravização ilegal e precarização da liberdade no Brasil Império. In: AZEVEDO, Elciene. et al. (Orgs.) Trabalhadores na cidade: cotidiano e cultura no Rio de Janeiro e em São Paulo, séculos XIX e XX. Campinas: Editora da Unicamp, 2009. p. 23-62.

. Visões da liberdade: uma história das últimas décadas da escravidão na corte. São Paulo: Companhia das letras, 1990.

FERREIRA SOBRINHO, José H. “Catirina, minha Nêga, tão querendo te vendê...”: escravidão, tráfico e negócios no Ceará do século XIX (1850-1881). Fortaleza: SECULT/ CE, 2011.

FREITAS, Letícia G. B. de. Escravos nos tribunais: o recurso à legislação emancipacionista em ações de liberdade do século XIX. Monografia (Graduação em História) - Universidade Estadual de Campinas, Campinas. 2012.

GRAHAM, Richard. Nos Tumbeiros Mais Uma Vez? O Comércio Interprovincial de escravos no Brasil. Revista Afro- Asia, Salvador, UFBA, n. 27, p.121-160, 2002.

MACHADO, Maria H. P. T. O plano e o pânico: os movimentos sociais na década da Abolição. Rio de Janeiro: Editora UFRJ; EDUSP, 1994. 
Notas de Pesquisa

Crime e escravidão: trabalho, luta e resistência nas lavouras paulistas, 1830-1888. São Paulo: Brasiliense, 1987.

OLIVEIRA, Joice F. de S. Forasteiros no Oeste Paulista: escravos no comércio interno de cativos e suas experiências em Campinas, 1850-1888. Dissertação (Mestrado em História) - Universidade Estadual de Campinas, Campinas. 2013.

PENA, Eduardo Spiller. Burlas à lei e revolta escrava no tráfico interno do Brasil meridional, século XIX. In: LARA, Silvia H.; MENDONÇA, Joseli M. N. (Orgs.). Direitos e justiças no Brasil: Ensaios de história social. Campinas: Editora da Unicamp, 2006. p.161-197.

ROCHA, Cristiany M. Histórias de Famílias Escravas. Campinas: Editora da Unicamp, 2004.

SLENES, Robert. Grandeza ou decadência? O mercado de escravos e a economia cafeeira da província do Rio de Janeiro, 1850-1888. In: COSTA, Iraci. (Org.). Brasil: história econômica e demográfica. São Paulo: Instituto de Pesquisas Econômicas, USP, 1986. p.103-155.

. The demography and economics of Brazilian slavery. Tese de Ph.D., Stanford University, 1976. 